\title{
Thiazolidinediones reduce the LDL binding affinity of non-human primate vascular cell proteoglycans
}

\author{
L. R. Tannock ${ }^{1}$ P. J. Little ${ }^{2}$ C. Tsoi ${ }^{3}$ P. H. R. Barrett ${ }^{4}$ T. N. Wight ${ }^{3}$ A. Chait $^{1}$ \\ ${ }^{1}$ Department of Medicine, University of Washington, Seattle, USA \\ 2 Baker Medical Research Institute, Melbourne, Victoria, Australia \\ ${ }^{3}$ Department of Pathology, University of Washington, and Hope Heart Institute, Seattle, Washington, USA \\ ${ }^{4}$ Department of Medicine, Western Australia Institute for Medical Research, University of Western Australia, Perth, Australia
}

\section{Abstract}

Aims/hypothesis. Retention of atherogenic lipoproteins in the artery wall by proteoglycans is a key step in the development of atherosclerosis. Thiazolidinediones have been shown to reduce atherosclerosis in mouse models. The aim of this study was to determine whether thiazolidinediones modify vascular proteoglycan synthesis in a way that decreases LDL binding. Methods. Primate aortic smooth muscle cells were exposed to troglitazone or rosiglitazone, or no stimulus at all for a 24-hour steady-state labelling period. Sulphate incorporation, size and LDL binding affinity of proteoglycans were determined. Proteoglycans secreted by cells in the presence or absence of troglitazone were separated into large and small classes by size exclusion chromatography, and LDL binding affinity was determined.

Results. Proteoglycans synthesised by cells exposed to troglitazone or rosiglitazone were smaller, with de- creased sulphate incorporation and decreased LDL binding affinity. However, troglitazone had a greater effect than rosiglitazone. Troglitazone reduced the LDL binding affinities of both the large and small proteoglycans compared with control. The binding differences persisted when glycosaminoglycan chains released from proteoglycans were incubated with LDL, indicating that troglitazone affects the glycosaminoglycan synthetic machinery of these cells.

Conclusions/interpretation. Thiazolidinediones decrease the LDL binding affinity of the proteoglycans synthesised by primate aortic smooth muscle cells. This could, in part, account for the reduced atherosclerosis observed in animal models.

Keywords Atherosclerosis - Glycosaminoglycans . Lipoprotein retention - Proteoglycans - Rosiglitazone • Thiazolidinediones · Troglitazone.
Received: 3 November 2003 / Accepted: 19 December 2003

Published online: 8 April 2004

(C) Springer-Verlag 2004

A. Chait (®)

Department of Medicine, University of Washington,

Seattle, WA 98195-6426 USA

E-mail: achait@u.washington.edu

Tel.: +1-206-5433158, Fax: +1-206-6858346

Abbreviations: PPAR $\gamma$, peroxisome proliferator-activated receptor $\gamma \cdot \mathrm{K}_{\mathrm{d}}$, binding constant

Presented in part at the 3rd Annual Conference on Arteriosclerosis, Thrombosis and Vascular Biology, Salt Lake City, Utah, USA, 6 April 2002

\section{Introduction}

Type 2 diabetes is characterised by hyperglycaemia, insulin resistance and often central obesity. Atherosclerotic complications continue to be a major cause of morbidity and mortality in persons with diabetes. Thiazolidinediones, a class of peroxisome proliferator-activated receptor $\gamma$ (PPAR $\gamma$ ) ligands, have been shown to decrease atherosclerosis in animal models [1, 2, 3, 4]. Thiazolidinediones have several potential anti-atherogenic properties, including inhibition of smooth muscle cell [5] and endothelial cell proliferation [6], improvements in fibrinolysis [7] and decreases in carotid artery intima-media thickness [8]. Although the effect of thiazolidinediones on clinical 
cardiovascular events in individuals with Type 2 diabetes is unknown due to the short duration of availability, troglitazone was shown to inhibit the formation of atherosclerotic lesions in diabetic and non-diabetic male LDL-receptor-deficient mice [2]. The diabetic and non-diabetic mice differed in their glycaemic responses to troglitazone, yet both groups had decreased lesion formation suggesting a direct vascular effect of troglitazone separate from its metabolic effects [2]. Troglitazone supplementation also inhibited the formation of atherosclerotic lesions in male apolipoprotein-E-deficient mice [1]. Rosiglitazone was shown to decrease atherosclerosis development in male LDL-receptor-deficient mice [3] and in diabetic and non-diabetic male apolipoprotein-E-deficient mice [4]. Troglitazone and rosiglitazone were shown to decrease the development of glomerulosclerosis in rats $[9,10,11]$. In one of these studies, the kidneys were stained for the glomerular mesangial basement membrane chondroitin sulphate proteoglycans, and the data suggested that the inhibitory effect of troglitazone on diabetic glomerulosclerosis may be related to reduced proteoglycan synthesis [10].

Proteoglycans are thought to play a critical role in the development of atherosclerosis, as outlined in the response to retention hypothesis [12]. Proteoglycans are a heterogeneous group of complex molecules, composed of a core protein to which one or more glycosaminoglycan chains are attached [13]. Proteoglycans bind lipoproteins through ionic interactions between negatively charged sulphate and carboxyl groups on their glycosaminoglycan side chains and positively charged amino acid residues on the apolipoproteins, or through linking molecules such as lipoprotein lipase [14]. Proteoglycans are ubiquitous in the arterial wall, and are mainly synthesised by vascular smooth muscle cells. The major proteoglycans synthesised by vascular smooth muscle cells are the large chondroitin sulphate proteoglycan, versican, the small dermatan sulphate proteoglycans, biglycan and decorin, and the heparan sulphate proteoglycan, perlecan [15]. The critical role of proteoglycans in the pathogenesis of atherosclerosis was demonstrated in a study of mice that were transgenic for human apolipoprotein B100 and that expressed either proteoglycan-binding-defective apolipoprotein B100 or proteoglycan-binding-intact apolipoprotein B100. At equal cholesterol levels, the mice expressing proteoglycan-binding-defective apolipoprotein B100 had significantly less atherosclerosis [16]. This demonstrates the critical role of proteoglycan binding in the retention of atherogenic lipoproteins in the development of atherosclerosis.

In this paper we present data demonstrating that exposure of vascular smooth muscle cells to thiazolidinediones leads to the synthesis of proteoglycans with reduced binding affinity for LDL, which could, in part, account for the reduced atherosclerosis observed with the thiazolidinediones in animal models.

\section{Materials and methods}

Materials. Chemicals and reagents were obtained from Sigma (St. Louis, Mo., USA) unless otherwise specified. Radioactive sulphate was obtained from ICN (Costa Mesa, Calif., USA). Troglitazone (Parke-Davis Pharmaceutical Research, Ann Arbor, Mich., USA) and rosiglitazone (GlaxoSmithKline, Dandenong, Vic, Australia) were dissolved in DMSO, then added directly to the culture media.

Cell culture techniques. Monkey (Macaca nemestrina) arterial smooth muscle cells were cultured in DMEM containing $5.6 \mathrm{mmol} / \mathrm{l}$ glucose as described previously [17]. Confluent cells were made quiescent for $48 \mathrm{~h}$ by lowering the serum concentration to $0.1 \%$, and were metabolically labelled with 1.85 to $3.7 \mathrm{mBq} / \mathrm{ml}\left[{ }^{35} \mathrm{~S}\right]-\mathrm{SO}_{4}$ for $24 \mathrm{~h}$ in the presence or absence of troglitazone or rosiglitazone. Parallel dishes were treated identically except without $\left[{ }^{35} \mathrm{~S}\right]-\mathrm{SO}_{4}$ labelling, and either cells were washed with PBS, trypsinised and counted in a Coulter counter, or cell protein was determined by the method of Lowry [18].

Proteoglycan isolation and characterisation. Sulphate incorporation was assessed by cetylpyridinium chloride precipitation [17]. The relative sulphate incorporation was assessed as a percentage of sulphate incorporation into proteoglycans synthesised by control vascular smooth muscle cells (not exposed to thiazolidinediones) $[19,20,21]$. Metabolically labelled cell culture medium was collected in the presence of protease inhibitors as described previously [20, 22]. Secreted proteoglycans from the different experiments were concentrated and purified using separate diethylaminoethyl-sephacel mini-columns $[20,22]$. Proteoglycans were separated into large (peak 1, containing predominantly the chondroitin sulphate proteoglycan, versican $[20,23]$ ) and small (peak 2, containing a mixture of dermatan sulphate proteoglycans, biglycan and decorin [24]) size classes using size exclusion chromatography [14, 25]. Glycosaminoglycan chains were released from core proteins as described previously [20].

LDL binding assay. As described previously, LDL was isolated from the plasma of normal human volunteers by preparative ultracentrifugation, and purified by sequential density gradient ultracentrifugation [26, 27]. LDL was stored under nitrogen in the dark at $4{ }^{\circ} \mathrm{C}$ with $1 \mathrm{mmol} / \mathrm{l}$ EDTA. A modified gel mobility shift assay was used to evaluate the LDL binding affinity of proteoglycans or free glycosaminoglycan chains synthesised in the presence or absence of troglitazone as described previously $[17,28]$. The percentage of proteoglycans or glycosaminoglycans bound was calculated as the proportion of radioactivity remaining at the gel's origin relative to the total radioactivity per lane. Binding constants $\left(\mathrm{K}_{\mathrm{d}}\right)$ were calculated using the Software Architecture Analysis Method II modelling program (SAAM Institute, Seattle, Wash., USA) using the MichaelisMenten equation.

Statistical analysis. Results are expressed as means \pm SEM unless otherwise noted. Results from LDL binding experiments were analysed using paired $t$ tests. All other comparisons were made using a two-tailed Student's $t$ test, with a $p$ value of less than 0.05 considered statistically significant. 


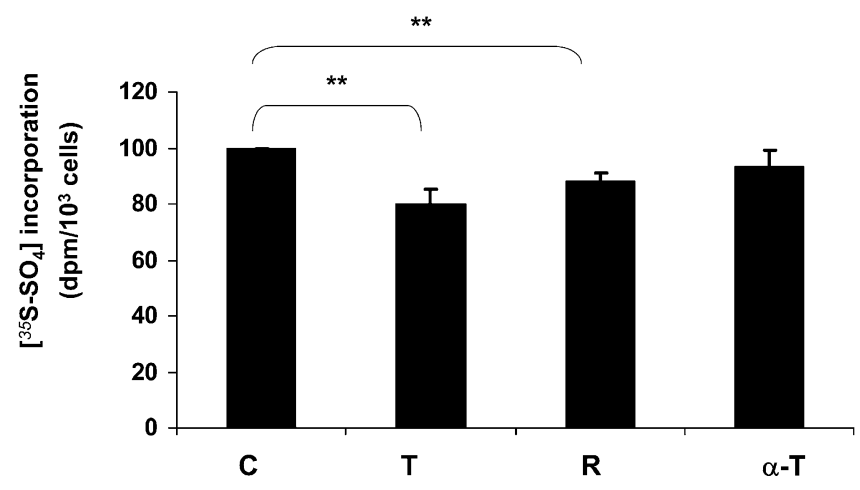

Fig. 1. Proteoglycan sulphate incorporation is reduced by treatment of vascular smooth muscle cells with troglitazone or rosiglitazone. Vascular smooth muscle cells were exposed to troglitazone $(10 \mu \mathrm{mol} / \mathrm{l})$, rosiglitazone $(30 \mu \mathrm{mol} / \mathrm{l})$ or $\alpha$-tocopherol $(10 \mu \mathrm{mol} / \mathrm{l})$ for $24 \mathrm{~h}$ and metabolically labelled with $\left[{ }^{35} \mathrm{~S}\right]-\mathrm{SO}_{4}$. The sulphate incorporation of proteoglycans secreted into the culture medium was analysed by cetylpyridinium chloride precipitation, and is expressed as incorporated sulphate counts per $10^{3}$ cells. Values are expressed as means \pm SEM relative to unstimulated cells, which are expressed as $100 \%$. Data are from two independent experiments performed in triplicate. $\mathrm{C}$, control; $\mathrm{T}$, troglitazone; $\mathrm{R}$, rosiglitazone; $\alpha-\mathrm{T}$, $\alpha$-tocopherol; ** $*<0.01$

\section{Results}

Dose-response experiments indicated that troglitazone had near-maximal effect on proteoglycan synthesis at $10 \mu \mathrm{mol} / \mathrm{l}$, with toxicity developing at $30 \mu \mathrm{mol} / \mathrm{l}$ as shown by loss of cells. Rosiglitazone had maximal effect on proteoglycan synthesis at $30 \mu \mathrm{mol} / \mathrm{l}$, with toxicity developing at $50 \mu \mathrm{mol} / \mathrm{l}$.

The LDL binding affinities of total secreted proteoglycans synthesised in the presence of either troglitazone $\left(\mathrm{K}_{\mathrm{d}} 0.029 \pm 0.006 \mathrm{mg} / \mathrm{ml} \mathrm{LDL}, p=0.008\right.$ compared with control) or rosiglitazone $\left(\mathrm{K}_{\mathrm{d}} 0.024 \pm 0.002 \mathrm{mg} / \mathrm{ml}\right.$ LDL, $p=0.01$ compared with control) were less than that of control proteoglycans $\left(\mathrm{K}_{\mathrm{d}} 0.016 \pm 0.004 \mathrm{mg} / \mathrm{ml}\right.$ LDL). Troglitazone had a greater effect in reducing LDL binding affinity than rosiglitazone.

We and others have previously demonstrated that decreased LDL binding affinity is mediated via smaller proteoglycans and glycosaminoglycans $[17,29]$. To determine whether the thiazolidinediones alter the steady-state levels of newly synthesised vascular proteoglycans, the incorporation of radiolabelled sulphate into proteoglycans was assessed. Troglitazone reduced the incorporation of sulphate to $80.1 \pm 5.3 \%$ of that of control $(p<0.01$; Fig. 1$)$. Rosiglitazone also reduced sulphate incorporation, although the magnitude of reduction was not as great as that with troglitazone. Troglitazone is unique amongst thiazolidinediones in that it has an $\alpha$-tocopherol moiety. To determine whether the greater reduction of sulphate incorporation by troglitazone compared with that by rosiglitazone was in part mediated by the $\alpha$-tocopherol moiety,

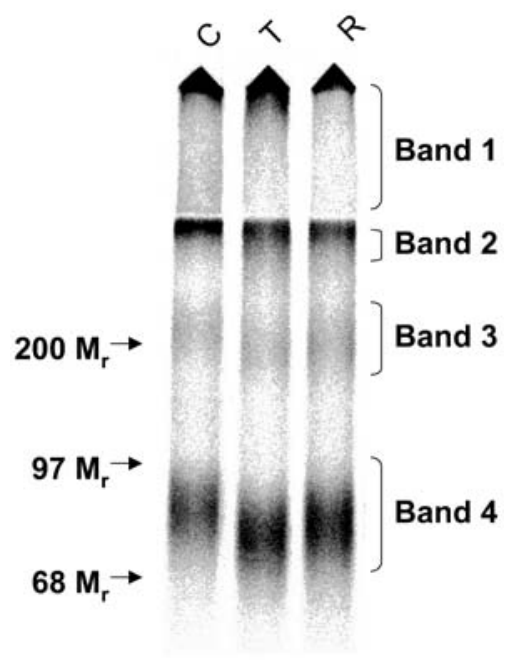

Fig. 2. SDS-PAGE (3.5\% stacking gel with $4-12 \%$ gradient resolving gel) analysis of radiolabelled secreted proteoglycans synthesised in the absence or presence of troglitazone $(10 \mu \mathrm{mol} / \mathrm{l})$ or rosiglitazone $(30 \mu \mathrm{mol} / \mathrm{l})$ for $24 \mathrm{~h}$. Proteoglycans synthesised by cells exposed to troglitazone or rosiglitazone are smaller than those synthesised by control cells. Lanes are loaded with $25,000 \mathrm{dpm}$. The gel shown is representative of seven independent experiments. C, control; T, troglitazone; $\mathrm{R}$, rosiglitazone

we also exposed cells to $\alpha$-tocopherol alone in equimolar concentrations. $\alpha$-Tocopherol did not affect sulphate incorporation (Fig. 2), nor did it have any additive effect when added to cells in combination with rosiglitazone.

The apparent molecular weight of proteoglycans synthesised in the presence and absence of thiazolidinediones was evaluated using SDS-PAGE. Vascular smooth muscle cells secrete four major proteoglycans that are seen on SDS-PAGE. Band 1 has previously been identified as the chondroitin sulphate proteoglycan, versican $[20,23]$. Band 2 is a mixture of heparan sulphate and chondroitin sulphate proteoglycans that has not been described in detail. These bands do not enter the resolving gel, and thus the effect of troglitazone on their size cannot be assessed by this method. The other major proteoglycans, biglycan (band 3) and decorin (band 4) [24], synthesised in the presence of troglitazone and rosiglitazone, had increased mobility compared with control proteoglycans, indicating smaller apparent molecular weights and/or altered charge (Fig. 2). To determine whether the increased mobility of proteoglycans was due to smaller size, proteoglycans were separated according to hydrodynamic size. Given that troglitazone had a greater effect than rosiglitazone on size, sulphate incorporation and LDL binding affinity, further characterisation studies were performed comparing proteoglycans synthesised in the presence or absence of troglitazone. Analysis using molecular sieve chromatography demonstrated that peak 1 (containing predominantly versican) and peak 2 


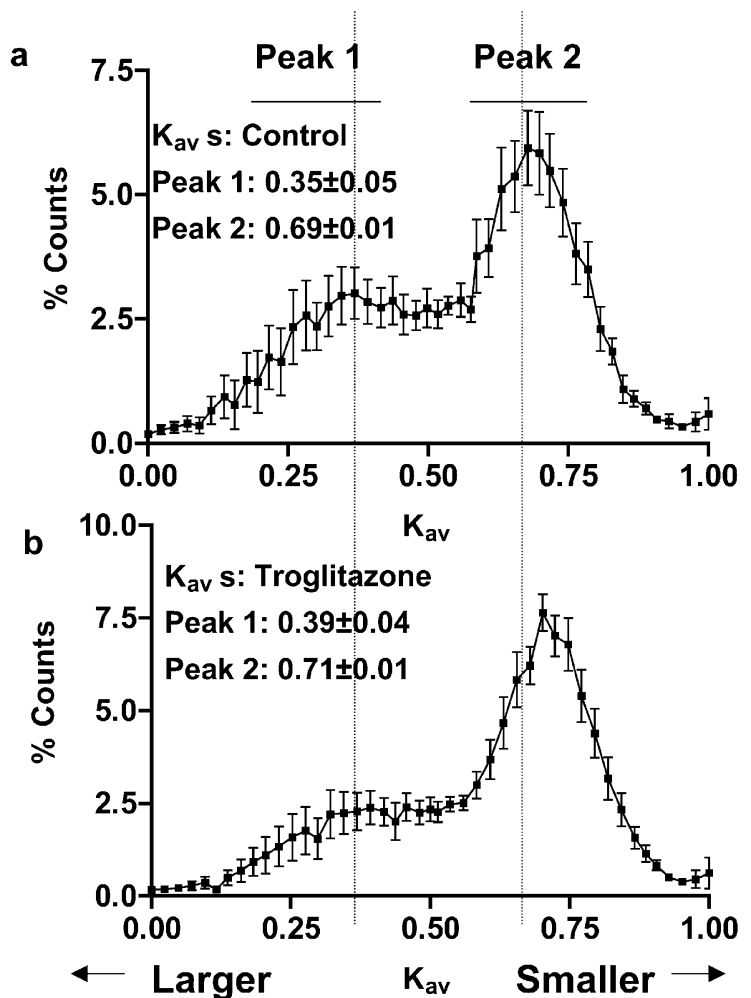

Fig. 3. Troglitazone decreases the size of both large and small proteoglycans. Secreted proteoglycans synthesised in the absence (a) or presence (b) of troglitazone were applied to Sepharose 2B columns for size analysis by molecular sieve chromatography. The curves shown are the means \pm SEM of seven independent experiments. The dotted vertical lines indicate the mean $\mathrm{K}_{\mathrm{av}} \mathrm{s}$ for peak 1 and peak 2 proteoglycans synthesised by control cells. Fractions eluting under the horizontal bars as indicated were pooled separately into peak 1 (versican) and peak 2 (biglycan and decorin) for use in subsequent experiments (containing predominantly biglycan and versican) [14, 25] proteoglycans synthesised in the presence of troglitazone were smaller than proteoglycans synthesised by control cells (peak $1, \mathrm{~K}_{\mathrm{av}} 0.35 \pm 0.05$ vs $0.39 \pm 0.04, n=6$, $p=0.04$; peak $2 \mathrm{~K}_{\mathrm{av}} 0.69 \pm 0.01$ vs $0.71 \pm 0.009, n=6$, $p=0.05$, in the absence and presence of troglitazone respectively; Fig. 3). Thus, troglitazone stimulation of vascular smooth muscle cells results in a decrease in size of all major secreted proteoglycans. Furthermore, troglitazone did not affect the relative synthesis of peak 1 and 2 proteoglycans, as areas under the peaks are not significantly different for peak 1 or peak 2 proteoglycans synthesised in the presence or absence of troglitazone. Thus, the decreased sulphate incorporation (Fig. 1) is probably distributed amongst all major secreted proteoglycans.

To determine whether troglitazone had different effects on the binding of the large chondroitin sulphate proteoglycan, versican, compared with the small dermatan sulphate proteoglycans, biglycan and decorin, LDL binding affinity was assessed on proteoglycans separated into large and small size classes by preparative size exclusion chromatography. Fractions eluting under each peak were pooled (Fig. 3), and LDL binding affinity was assessed by a modified gel mobility shift assay.

Peak 1 and peak 2 proteoglycans synthesised in the presence of troglitazone each demonstrated a lower LDL binding affinity than control $\left(\mathrm{K}_{\mathrm{d}} 0.184 \pm 0.026 \mathrm{vs}\right.$ $0.047 \pm 0.005 \mathrm{mg} / \mathrm{ml} \mathrm{LDL}$ for peak 1 proteoglycans, $p<0.01 ; \mathrm{K}_{\mathrm{d}} 0.210 \pm 0.030$ vs $0.123 \pm 0.014 \mathrm{mg} / \mathrm{ml} \mathrm{LDL}$ for peak 2 proteoglycans, $p=0.02$, synthesised in the presence and absence of troglitazone respectively; Fig. 4), although there was a greater reduction of LDL binding affinity for peak 1 proteoglycans. To determine whether the effect of troglitazone (reducing LDL binding by proteoglycans) is mediated via their glycosaminoglycan chains, we assessed the LDL binding af- a

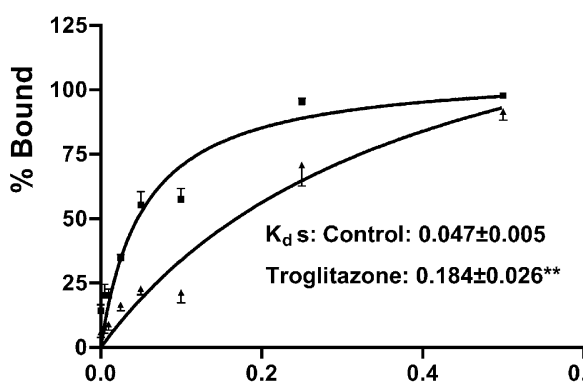

b

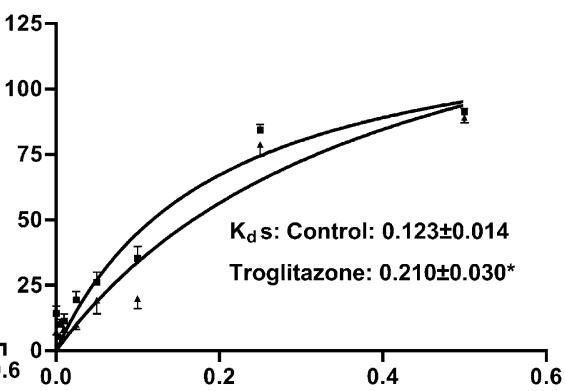

\section{$\operatorname{LDL}(\mathrm{mg} / \mathrm{ml})$}

Fig. 4. Troglitazone decreases the LDL binding affinity of both large and small proteoglycans. Equal amounts of peak 1 proteoglycans (a) and peak 2 proteoglycans (b) synthesised by cells exposed to troglitazone (triangles) or no stimulus (control, squares) were used in a modified gel mobility shift assay. The percentage of proteoglycan bound was calculated as the proportion of radioactivity remaining at the origin of the gel relative to the total radioactivity per lane. The binding curves shown are the means \pm SEM of two independent experiments, each performed in duplicate. ${ }^{*} p<0.01 ; * p=0.02 ; \mathrm{K}_{\mathrm{d}}$, binding constant 
a

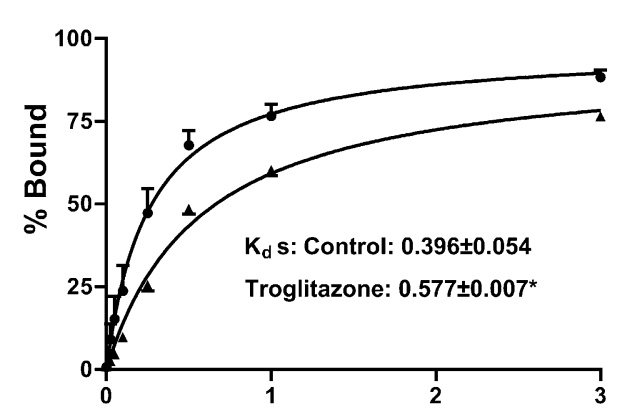

b

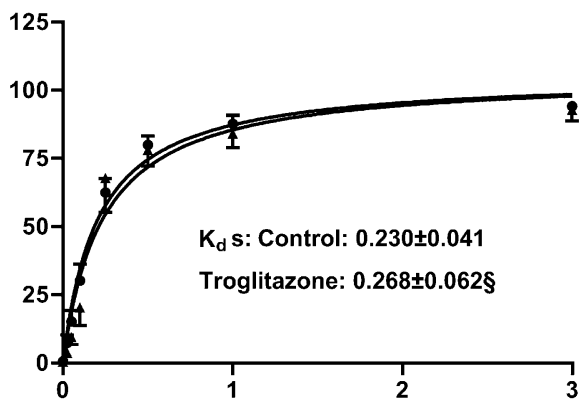

LDL $(\mathrm{mg} / \mathrm{ml})$

Fig. 5. Peak 1 glycosaminoglycans synthesised in the presence of troglitazone have reduced LDL binding affinity. Glycosaminoglycans cleaved from peak 1 (a) or peak 2 (b) proteoglycans synthesised by cells exposed to troglitazone (triangles) or no stimulus (control, squares) were used in a gel mobility shift assay. The percentage of glycosaminoglycan bound was calculated as the proportion of radioactivity remaining at the gel's origin relative to the total radioactivity per lane. The binding curves shown are the means \pm SEM of two independent experiments each performed in duplicate. ${ }^{*} p=0.03$; $\S$, NS; $\mathrm{K}_{\mathrm{d}}$, binding constant

finity of peak 1 and peak 2 glycosaminoglycan chains. Glycosaminoglycan chains cleaved from peak 1 proteoglycans synthesised in the presence of troglitazone had lower binding affinity for LDL compared with glycosaminoglycans synthesised by unexposed cells $\left(\mathrm{K}_{\mathrm{d}}\right.$ $0.577 \pm 0.007$ vs $0.396 \pm 0.054 \mathrm{mg} / \mathrm{ml}$ LDL respectively, $p=0.03$; Fig. 5a). However, we were unable to detect a significant alteration in LDL binding affinity for glycosaminoglycan chains cleaved from peak 2 proteoglycans synthesised in the presence or absence of troglitazone $\left(\mathrm{K}_{\mathrm{d}} 0.268 \pm 0.062\right.$ vs $0.230 \pm 0.041 \mathrm{mg} / \mathrm{ml} \mathrm{LDL}$ respectively, NS; Fig. 5b).

\section{Discussion}

The data presented here demonstrate that primate vascular smooth muscle cells exposed to troglitazone or rosiglitazone synthesise smaller proteoglycans with reduced LDL binding affinity, although troglitazone has greater effects than rosiglitazone on proteoglycan synthesis. The effect of troglitazone to reduce the LDL binding affinity of peak 1 proteoglycans is mediated through its glycosaminoglycan chains. However, we did not detect a significant difference in the LDL binding affinity of peak 2 glycosaminoglycan chains synthesised in the presence versus absence of troglitazone. Our inability to demonstrate decreased LDL binding affinity for peak 2 glycosaminoglycans synthesised in the presence of troglitazone could be due to a limitation of the assay, or to troglitazone having less of an effect on the LDL binding affinity of dermatan sulphate chains than on that of chondroitin sulphate chains. The LDL binding affinity of free glycosaminoglycan chains is lower than the binding affinity of intact proteoglycans, as previously described [17, 30].

Versican is the predominant component of peak 1 [20] and is composed of a core protein to which 15 to 20 chondroitin sulphate glycosaminoglycans are attached [13, 31]. Peak 2 is composed of biglycan and decorin [24] which have dermatan sulphate glycosaminoglycan chains. Biglycan has 2 glycosaminoglycans, while decorin has only a single glycosaminoglycan chain [13]. Our laboratory has previously demonstrated that purified versican has a greater binding capacity for LDL than purified biglycan [14], which is probably due to the greater number of glycosaminoglycan chains on versican than on biglycan.

We have previously demonstrated that LDL binding affinity of intact proteoglycans and glycosaminoglycan chains relates to the relative size and sulphation of the molecules $[17,30]$. In the present experiments we confirm these previous observations, demonstrating that proteoglycans synthesised in the presence of troglitazone or rosiglitazone are smaller and have decreased LDL binding affinity. Decreased sulphate incorporation is usually due to a decreased size of proteoglycans, which in turn is due to decreased length of their glycosaminoglycan chains. The mechanism by which these thiazolidinediones exert their effects is not clear. Vascular smooth muscle cells have been shown to express PPAR $\gamma$ [5]. Therefore, these thiazolidinediones may exert their effects on glycosaminoglycan chains via this class of nuclear receptors. The synthesis of glycosaminoglycan chains is complex and involves multiple enzymes including sulphotransferases, xylosyltransferases, galactosyltransferases and others $[13,32,33]$. PPAR $\gamma$ has been shown to decrease extracellular signal-regulated kinase and mitogen-activated protein kinases, but to increase phosphatidylinositol-3 kinase signalling [34]. Further studies into the signalling pathways by which 
troglitazone exerts its effects are underway. In addition, we have shown that thiazolidinediones decrease human vascular smooth muscle cell proliferation [35]. Their effect to inhibit proteoglycan synthesis may be related to their inhibitory effects on proliferation.

Although troglitazone is no longer used clinically due to hepatotoxicity, we demonstrate that rosiglitazone, but not $\alpha$-tocopherol, has a similar effect: it decreases sulphate incorporation. Rosiglitazone also decreases the size and LDL binding affinity of the vascular proteoglycans, although to a lesser extent than troglitazone. This suggests that the observed effects of troglitazone on proteoglycan synthesis are due to its thiazolidinedione moiety, rather than to its $\alpha$-tocopherol moiety. Several different thiazolidinediones have been reported to decrease atherosclerosis in animal models [1, 2, 3, 4]. Therefore, we suggest that the effects of troglitazone on proteoglycan synthesis described here are class effects. Although troglitazone is no longer clinically available and thus not a potential anti-atherosclerosis therapy, it is still useful as a tool to manipulate glycosaminoglycan synthesis. An increased understanding of glycosaminoglycan synthesis will allow identification of novel therapeutic targets and potential anti-atherosclerosis or atherosclerosis-preventing therapies. The critical role played by proteoglycan-mediated LDL retention in the development of atherosclerosis [16] suggests that strategies to modify arterial wall proteoglycans have potential clinical impact.

In summary, the data presented in this paper suggest a mechanism for the observed decrease in atherosclerosis seen in animal models treated with thiazolidinediones. A decrease in the binding affinity of vascular proteoglycans for atherogenic lipoproteins caused by troglitazone or rosiglitazone exposure could account for reduced atherosclerotic lesions described in the literature. Since the effects described here are probably class effects of thiazolidinediones, the potential clinical benefits of thiazolidinediones for reducing atherosclerosis development or progression are significant. Long-term clinical trials with cardiovascular outcomes are needed to confirm this hypothesis. However, the different thiazolidinediones may have differing effects on atherosclerosis that are independent of their relative affinities for PPAR $\gamma$.

Acknowledgements. This work was supported in part by National Institutes of Health grants DK35816 (L. R. Tannock), HL18645 (T. N. Wight), AT00555 (L. R. Tannock) and DK02456 (A. Chait and T. N. Wight) and a grant from the Diabetes Australia Research Trust (P. J. Little). P. H. R. Barrett is a Career Development Fellow of the National Heart Foundation and is supported in part by a grant from the National Institutes of Health (RR12609). The authors thank Mohamed Omer and Shari Wang for expert technical assistance. The laboratory facilities of the University of Washington Diabetes Endocrinology Center were used (NIH grant; DK17047).

\section{References}

1. Chen Z, Ishibashi S, Perrey S et al. (2001) Troglitazone inhibits atherosclerosis in apolipoprotein E-knockout mice: pleiotropic effects on CD36 expression and HDL. Arterioscler Thromb Vasc Biol 21:372-377

2. Collins AR, Meehan WP, Kintscher U et al. (2001) Troglitazone inhibits formation of early atherosclerotic lesions in diabetic and nondiabetic low density lipoprotein receptordeficient mice. Arterioscler Thromb Vasc Biol 21:365371

3. Li AC, Brown KK, Silvestre MJ et al. (2000) Peroxisome proliferator-activated receptor gamma ligands inhibit development of atherosclerosis in LDL receptor-deficient mice. J Clin Invest 106:523-531

4. Levi Z, Shaish A, Yacov N et al. (2003) Rosiglitazone (PPARgamma-agonist) attenuates atherogenesis with no effect on hyperglycaemia in a combined diabetes-atherosclerosis mouse model. Diabetes Obes Metab 5:45-50

5. Law RE, Goetze S, Xi XP et al. (2000) Expression and function of PPARgamma in rat and human vascular smooth muscle cells. Circulation 101:1311-1318

6. Dios ST de, Hannan KM, Dilley RJ, Hill MA, Little PJ (2001) Troglitazone, but not rosiglitazone, inhibits $\mathrm{Na} / \mathrm{H}$ exchange activity and proliferation of macrovascular endothelial cells. J Diabetes Complications 15:120-127

7. Fonseca VA, Reynolds T, Hemphill D et al. (1998) Effect of troglitazone on fibrinolysis and activated coagulation in patients with non-insulin-dependent diabetes mellitus. J Diabetes Complications 12:181-186

8. Minamikawa J, Tanaka S, Yamauchi M, Inoue D, Koshiyama H (1998) Potent inhibitory effect of troglitazone on carotid arterial wall thickness in type 2 diabetes. J Clin Endocrinol Metab 83:1818-1820

9. Ma LJ, Marcantoni C, Linton MF, Fazio S, Fogo AB (2001) Peroxisome proliferator-activated receptor-gamma agonist troglitazone protects against nondiabetic glomerulosclerosis in rats. Kidney Int 59:1899-1910

10. McCarthy KJ, Routh RE, Shaw W et al. (2000) Troglitazone halts diabetic glomerulosclerosis by blockade of mesangial expansion. Kidney Int 58:2341-2350

11. Buckingham RE, Al-Barazanji KA, Toseland CD et al. (1998) Peroxisome proliferator-activated receptor-gamma agonist, rosiglitazone, protects against nephropathy and pancreatic islet abnormalities in Zucker fatty rats. Diabetes 47:1326-1334

12. Williams KJ, Tabas I (1995) The response-to-retention hypothesis of early atherogenesis. Arterioscler Thromb Vasc Biol 15:551-561

13. Wight TN (1999) Biosynthesis of proteoglycans. In: Pinto BM (ed) Comprehensive natural products chemistry. Elsevier, St. Louis, pp 161-177

14. Olin KL, Potter-Perigo S, Barrett PH, Wight TN, Chait A (1999) Lipoprotein lipase enhances the binding of native and oxidized low density lipoproteins to versican and biglycan synthesized by cultured arterial smooth muscle cells. J Biol Chem 274:34629-34636

15. Wight TN (1996) The vascular extracellular matrix. In: Fuster V, Ross R, Topol EJ (eds) Atherosclerosis and coronary artery disease. Lippincott-Raven, Philadelphia, pp 421-440

16. Skalen K, Gustafsson M, Rydberg EK et al. (2002) Subendothelial retention of atherogenic lipoproteins in early atherosclerosis. Nature 417:750-754

17. Tannock LR, Little PJ, Wight TN, Chait A (2002) Arterial smooth muscle cell proteoglycans synthesized in the presence of glucosamine demonstrate reduced binding to LDL. J Lipid Res 43:149-157 
18. Lowry OH, Rosebrough NJ, Farr AL, Randall RJ (1951) Protein measurement with the Folin phenol reagent. J Biol Chem 193:265-275

19. Wasteson A, Uthne K, Westermark B (1973) A novel assay for the biosynthesis of sulphated polysaccharide and its application to studies on the effects of somatomedin on cultured cells. Biochem J 136:1069-1074

20. Schonherr E, Jarvelainen HT, Sandell LJ, Wight TN (1991) Effects of platelet-derived growth factor and transforming growth factor, beta1 on the synthesis of a large versicanlike chondroitin sulfate proteoglycan by arterial smooth muscle cells. J Biol Chem 66:17640-17647

21. Camejo G, Fager G, Rosengren B, Hurt-Camejo E, Bondjers G (1993) Binding of low density lipoproteins by proteoglycans synthesized by proliferating and quiescent human arterial smooth muscle cells. J Biol Chem 268: 14131-14137

22. Schonherr E, Jarvelainen HT, Kinsella MG, Sandell LJ, Wight TN (1993) Platelet derived growth factor and transforming growth factor-betal differentially affect the synthesis of biglycan and decorin by monkey arterial smooth muscle cells. Arterioscler Thromb 13:1026-1036

23. Yao LY, Moody C, Schonherr E, Wight TN, Sandell LJ (1994) Identification of the proteoglycan versican in aorta and smooth muscle cells by DNA sequence analysis, in situ hybridization and immunohistochemistry. Matrix Biol 14:213-225

24. Jarvelainen HT, Kinsella MG, Wight TN, Sandell LJ (1991) Differential expression of small chondroitin/dermatan sulfate proteoglycans, PG-I/biglycan and PG-II/ decorin, by vascular smooth muscle and endothelial cells in culture. J Biol Chem 266:23274-23281

25. Wight TN, Hascall VC (1983) Proteoglycans in primate arteries. III. Characterization of the proteoglycans synthesized by arterial smooth muscle cells in culture. J Cell Biol 96:167-176
26. Chung BH, Wilkinson T, Geer JC, Segrest JP (1980) Preparative and quantitative isolation of plasma lipoproteins: rapid, single discontinuous density gradient ultracentrifugation in a vertical rotor. J Lipid Res 21:284-291

27. Heinecke JW, Baker L, Rosen H, Chait A (1986) Superoxide-mediated free radical modification of low density lipoprotein by arterial smooth muscle cells. J Clin Invest 77:757-761

28. Hurt-Camejo E, Camejo G, Sartipy P (1998) Measurements of proteoglycan-lipoprotein interaction by gel mobility shift assay. Methods Mol Biol 110:267-279

29. Vijayagopal P, Subramaniam P (2001) Effect of calcium channel blockers on proteoglycan synthesis by vascular smooth muscle cells and low density lipoprotein-proteoglycan interaction. Atherosclerosis 157:353-360

30. Little PJ, Tannock L, Olin KL, Chait A, Wight TN (2002) Proteoglycans synthesized by arterial smooth muscle cells in the presence of transforming growth factor-beta1 exhibit increased binding to LDLs. Arterioscler Thromb Vasc Biol 22:55-60

31. Wight T (2002) Versican: a versatile extracellular matrix proteoglycan in cell biology. Curr Opin Cell Biol 14:617

32. Prydz K, Dalen KT (2000) Synthesis and sorting of proteoglycans. J Cell Sci 113 Pt 2:193-205

33. Sugahara K, Kitagawa H (2000) Recent advances in the study of the biosynthesis and functions of sulfated glycosaminoglycans. Curr Opin Struct Biol 10:518-527

34. Hsueh WA, Law RE (2001) PPARgamma and atherosclerosis: effects on cell growth and movement. Arterioscler Thromb Vasc Biol 21:1891-1895

35. Dios ST de, Bruemmer D, Dilley RJ et al. (2003) Inhibitory activity of clinical thiazolidinedione peroxisome proliferator activating receptor-gamma ligands towards internal mammary artery, radial artery and saphenous vein smooth muscle cell proliferation. Circulation 107:25482550 